\title{
How to carve across the joints in nature without abandoning Kripke-Putnam semantics
}

DOI:

10.1093/acprof:oso/9780199674527.001.0001

\section{Document Version}

Accepted author manuscript

Link to publication record in Manchester Research Explorer

\section{Citation for published version (APA):}

Beebee, H. (2013). How to carve across the joints in nature without abandoning Kripke-Putnam semantics. In S. Mumford, \& M. Tugby (Eds.), Metaphysics and Science Oxford University Press.

https://doi.org/10.1093/acprof:oso/9780199674527.001.0001

\section{Published in:}

Metaphysics and Science

\section{Citing this paper}

Please note that where the full-text provided on Manchester Research Explorer is the Author Accepted Manuscript or Proof version this may differ from the final Published version. If citing, it is advised that you check and use the publisher's definitive version.

\section{General rights}

Copyright and moral rights for the publications made accessible in the Research Explorer are retained by the authors and/or other copyright owners and it is a condition of accessing publications that users recognise and abide by the legal requirements associated with these rights.

\section{Takedown policy}

If you believe that this document breaches copyright please refer to the University of Manchester's Takedown Procedures [http://man.ac.uk/04Y6Bo] or contact uml.scholarlycommunications@manchester.ac.uk providing relevant details, so we can investigate your claim.

\section{OPEN ACCESS}




\section{How to carve across the joints in nature without abandoning Kripke-Putnam semantics ${ }^{1}$}

Helen Beebee

Please do not cite this version. The published version is: 'How to Carve Nature Across the Joints Without Abandoning Kripke-Putnam Semantics', in S. Mumford \& M. Tugby (eds.), Metaphysics and Science (Oxford: OUP, 2013).

\section{Introduction}

The topic of this paper is the connection - or rather, I shall argue, the lack of connection - between what I shall call 'natural kind essentialism' on the one hand and the Kripke-Putnam semantics for natural kind terms ('KP' for short). Natural kind essentialism is not a well-defined philosophical position, and in particular the question of exactly what one is committed to when one is committed to 'essentialism' gets different answers from different authors in both 'essentialist' and 'antiessentialist' camps. ${ }^{2}$ For the purposes of this paper, I shall take natural kind essentialism to enshrine a commitment to three theses: first, that which natural kinds exist is a fully mind- and theory-independent matter; second, that natural kinds have intrinsic essences; and, third, that natural kinds have a hierarchical structure (what Tobin 2010 calls the 'hierarchy thesis'). ${ }^{3}$

Those who endorse natural kind essentialism as just defined typically endorse Kripke and Putnam's claim that theoretical identifications, such as 'water is $\mathrm{H}_{2} \mathrm{O}$ ' and ' gold is the element with atomic number 79', are metaphysically necessary but knowable only a posteriori. ${ }^{4}$ Indeed, some go further and take the truth of this claim

\footnotetext{
${ }^{1}$ I am hugely indebted to Nigel Sabbarton-Leary, without whom I would never have been able to write this paper. Thanks also to Alexander Bird, Genoveva Martí, L. A. Paul, Emma Tobin, and many other people who heard and commented on a distant ancestor of this paper.

${ }^{2}$ For example, there is a large amount of middle ground in between the essentialist position defended by Brian Ellis (2001) and the anti-essentialist positions defended by Stephen Mumford (2005) and Paul Griffiths (1999). Joseph LaPorte $(2010,118)$ takes himself to be an essentialist, while John Dupré (2004) argues that he isn't (see Beebee and Sabbarton-Leary 2010c, 19-20 for a brief discussion of this latter dispute).

${ }^{3}$ Actually some defenders of natural kind essentialism subscribe to a weaker hierarchy thesis than this; see $\S 4$ below.

${ }^{4}$ An exception is Oderberg 2007.
} 
to constitute an argument in favour of natural kind essentialism. Nathan Salmon, by contrast, argues that the alleged necessary a posteriori status of theoretical identities is secured only by presupposing a 'nontrivial' essentialism at the outset; in other words, contra many of its defenders - and indeed some of its detractors - the semantics of natural kind terms just by itself does nothing to justify natural kind essentialism. I shall argue, however, that what Salmon regards as 'nontrivial' essentialism is in fact fairly trivial by the lights of most of contemporary metaphysics. In particular, it does not rule out various sorts of 'crosscutting' kinds; in particular, it rules out neither species pluralism (where some species concepts that one is pluralist about are ones that assign extrinsic essences to species) nor even - contrary to Putnam's original intentions - Kuhnian relativism. In other words, one can sign up to 'nontrivial' essentialism and still reject and or all of the three theses just described.

For all Salmon's argument tells us, then, once we endorse 'nontrivial' essentialism, KP may yet deliver a more substantive essentialism, namely one that entails the mind-independence and intrinsicness of natural-kind essences and the hierarchy thesis. The aim of this chapter is to show that it does not. In particular, natural kind essentialism - a highly nontrivial brand of essentialism that is incompatible with both species pluralism and Kuhnian relativism - is not entailed by KP (together with 'nontrivial' essentialism).

The basic idea is this. We have, on the one hand, the sorts of vernacular kind term that Kripke and Putnam were originally concerned with: 'gold', 'water', 'tiger', 'magpie', 'lemon', and so on. We correspondingly presuppose certain pre-theoretical sameness-of-kind relations: same substance, same animal, same fruit, and so on. In such cases, we defer (if KP is correct) to scientific investigation to tell us what it is for something to be the same $N K$ as something else for a given kind $N K$, where ' $N K$ ' refers to some higher-order kind - what I'll call a 'category' - that is pre-theoretically specificable (substance, fruit, and so on) and the vernacular kind term designates the relevant lower-level natural kind (gold and water are both kinds of substance, tiger and magpie are both kinds of animal, and so on).

On the other hand, we have natural kind terms that are manifestly not vernacular - 'electron', 'ununbium', 'enzyme', 'Coracias tibicen telonocua', and so on. In many such cases, no such pre-theoretical sameness-of-kind relation is so much as available to us. The blank in 'same ...' can only be filled in by appealing to the classificatory framework of the relevant science: elementary particle, element, 
species, and so on are no part of our pre-theoretical framework. In such cases, we defer to the classificatory framework of the relevant science not only to tell us what it is to be the same $N K$ as something else, for a given $N K$, but also to specify the category $N K$ itself. For example, there is no determinate answer, from the point of view of biology, to the question whether this (pointing at an African elephant) is the same animal as that (pointing at an Asian elephant): the answer is 'yes (if you mean "same family") and no (if you mean "same species" or "same genus")'. But 'same animal' does not determinately mean any one of these alternatives. In the case of, say, ununbium (the element with atomic number 112), it is unclear that one can even ask the relevant question without deploying the distinctively theoretical framework of the periodic table, since it is unclear that ununbium is a substance at all in the pretheoretical sense, given that it has a half-life of 0.24 milliseconds.

The upshot, I shall argue, is that once we leave vernacular kind terms and their associated categories (substance, animal, and so on) behind, as we must if we are to hold that for every natural kind there is some necessary a posteriori theoretical identity that specifies the essence of the kind, the 'essentialism' we are left with is, in the absence of further, independent metaphysical requirements on natural-kind essences that have nothing to do with KP, an extremely weak thesis that falls a very long way short of natural kind essentialism.

I shall proceed as follows. In $\S 2$, I very briefly outline KP and provide three examples of philosophers (Brian Ellis, John Dupré and Joseph LaPorte) who, I shall later argue, overstate the metaphysical implications of KP. In $\S 3$, I outline Nathan Salmon's 'OK-mechanism' - a template for deriving necessary a posteriori theoretical identifications - and argue that the sense of 'nontrivial' essentialism enshrined in its third premise enshrines is, in fact, a very weak form of essentialism. Hence the question remains whether KP (plus nontrivial essentialism) provides any justification for endorsing natural kind essentialism. In $\S 4$, I define four different ways in which a kind might be thought to 'cut across' nature's joints, and which one might hope (and, in some cases, some authors explicitly claim) are ruled out by KP. In $\S \S 5-7$, I take three of these varieties of crosscutting in turn (I leave artificial kinds to one side), and argue that none of them are, in fact, ruled out by KP. I conclude, in $\S 8$, by explaining how KP is consistent with a 'shallow' form of essentialism, in a sense roughly analogous to the 'shallow essentialism' defined for individuals in Paul 2006. Thus just as Kripke's account of the semantics of names does not - in the 
absence of independent substantive metaphysical assumptions - adjudicate between deep and shallow essentialism when it comes to individuals, so KP does not adjudicate between deep and shallow essentialism (in a slightly different sense) when it comes to kinds.

\section{The Kripke-Putnam Programme and the wonders it (allegedly) performs}

As is well known, according to Kripke 'theoretical identity statements' such as 'gold is the element with atomic number 79' and 'water is $\mathrm{H}_{2} \mathrm{O}$ ' are metaphysically necessary but knowable only a posteriori. So, for example, 'gold' rigidly designates the kind gold - 'gold' is a nondescriptive name for that kind ${ }^{5}$ - and the 'essence' of that kind (being the element with atomic number 79) is discovered by scientific investigation. Hence 'gold is the element with atomic number 79' is necessary if true, since if $E$ is the essence of $K$, all $K \mathrm{~s}$ will be $E \mathrm{~s}$, and vice versa, across all possible worlds. But it is knowable only a posteriori because only empirical investigation can reveal what gold's essence is. Thus:

[A] material object is (pure) gold if and only if the only element contained therein is that with atomic number 79. Here the 'if and only if' can be taken to be strict (necessary). In general, science attempts, by investigating basic structural traits, to find the nature, and thus the essence (in the philosophical sense) of the kind. (Kripke 1980: 138)

Putnam (1975) turns more or less the same trick, but without explicit appeal to essences. On his view:

When I say 'this (liquid) is water', the 'this' is, so to speak, a de re 'this' - i.e. the force of my explanation is that 'water' is whatever bears a certain equivalence relation [namely the same-liquid or same $_{L}$ relation] to the liquid referred to as 'this' in the actual world. $(1975,231)$

\footnotetext{
${ }^{5}$ The ontological status of natural kinds is a matter for dispute. In the philosophy of language, kinds are normally taken to be abstract objects, so that kind terms are genuine names of kinds; Devitt and Sterelny (1999), by contrast, take natural kind terms to 'rigidly apply' to members of their extensions, thus avoiding commitment to abstract objects. I shall proceed as though kind terms are names of kinds, but nothing directly relevant to the argument hangs on this.
} 
The same $_{L}$ relation is a 'theoretical relation - whether something is or is not the same liquid as this may take an indeterminate amount of scientific investigation to determine' $(1975,225)$ - and its cross-world import, giving us the rigidity of 'water', is demonstrated by the Twin Earth thought experiment. So we get the necessary status of 'water is $\mathrm{H}_{2} \mathrm{O}$ ' from the fact that the same $_{L}$ relation has cross-world import - at any possible world, something is the same liquid as this liquid if it bears the $s_{a m e}$ relation to it - and a posteriority from the fact that the $s \mathrm{me}_{L}$ relation is a relation whose obtaining is discovered by scientific investigation. Similarly for other ostensive definitions: " "this (animal) is a tiger"; "this (fruit) is a lemon"; where the parentheses are meant to indicate that the "markers" liquid, animal, fruit, may be explicit or implicit' $(1975,229)$.

So much for the machinery of necessary a posteriori theoretical identification; what of its metaphysical significance? The argument of this paper will be that its significance has been overstated, both by those who endorse KP and by those who reject it. Here is a selection of claims that have been made, starting with philosophers who endorse KP.

I'll start with Brian Ellis. Ellis (2001) has perhaps the most extreme conception of the significance of KP. On Ellis's view, which he dubs 'scientific essentialism', the laws of nature describe the essences of natural kinds (which include natural kinds of substance, process and property), and hence are metaphysically necessary. But what is it for a proposition to be metaphysically necessary? He says:

Analytic propositions are true in virtue in virtue of the meanings of words - that is, they depend for their truth on some conventionally established criterion for including something in some linguistically defined class. Metaphysically necessary propositions, on the other hand, are true in virtue of the essential natures of things - for example, they state correctly, or otherwise depend for their truth on, what makes something a thing of the natural kind it is. $(2001: 235)$

He goes on to explain how to distinguish between analytic truths on the one hand, and metaphysically necessary propositions on the other:

... one technique is to abstract from the descriptive language used to refer to [some class of objects], and replace the general name used with an ostensive 'kind-referring' 
expression, such as 'stuff of this kind' or 'things of this kind'. If the necessity survives this process, then we know that it cannot be grounded in the descriptive language we had been using. 'Water is $\mathrm{H}_{2} \mathrm{O}$ ', for example, clearly survives this test, because 'stuff of this kind is $\mathrm{H}_{2} \mathrm{O}$ ', said pointing to a glass of water, is no less necessary than 'water is $\mathrm{H}_{2} \mathrm{O}$ '. If there is any doubt about it, then it can only be a doubt about what the intended object of reference is [e.g. about whether one is referring to the glass or its contents], or ignorance about what its nature is. (2001: 235-6)

On Ellis's view, then, natural kind terms (and ostensive expressions) rigidly designate kinds whose essences are knowable only a posteriori ('stuff of this kind is $\mathrm{H}_{2} \mathrm{O}$ ' is manifestly not knowable a priori, and yet is metaphysically necessary, just as 'water is $\mathrm{H}_{2} \mathrm{O}$ ' is). And it is the a posteriority that tells us that the proposition in question is metaphysically necessary, or a matter of what he sometimes calls 'real necessity' - that is, 'true in virtue of the essential natures of things'. In other words, the existence of necessary a posteriori theoretical identifications is the cornerstone of scientific essentialism: it is KP that shows that there is such a thing as 'real necessity'.

Turning now to some philosophers hostile to KP but who nonetheless hold that it has significant implications, second up is Joseph LaPorte (2004). LaPorte argues that a broadly causal story about reference-fixing is consistent with a degree of 'vagueness' of reference at the pre-scientific stage at which reference (of, say, 'water' or 'gold') is fixed by the folk: 'causal baptisms, which according to the causal theory endow terms with their reference conditions, are performed by speakers whose conceptual development is not yet sophisticated enough to allow the speakers to coin a term in such a way as to preclude the possibility of open texture, or vague application not yet recognized' $(2004,118)$. The meaning of the term is then precisified by scientists at the point at which a decision needs to be made; hence scientists do not discover the essence of (say) water, but rather stipulate a new meaning. Hence - contrary to KP (though not, LaPorte argues, contrary to a broadly causal theory of reference that rejects a posteriori necessity) - 'water is $\mathrm{H}_{2} \mathrm{O}$ ' is necessary but not a posteriori: empirical investigation engenders a decision about whether to classify $\mathrm{D}_{2} \mathrm{O}$ as water, and so 'water is $\mathrm{H}_{2} \mathrm{O}$ ' turns out to be true by definition.

LaPorte's conclusion is that, because it does not deliver the full machinery of $\mathrm{KP}$, and in particular does not deliver necessary a posteriori theoretical identities, a 
broadly causal theory of reference does not block referential instability across theory change: it does not 'dispel the threat of incommensurability' (2004, 172). So LaPorte - along with Putnam (1975) himself - thinks KP itself does (or would, if true) dispel the threat of incommensurability. I shall argue in $§ 7$ that KP (suitably extended to cover all the natural kinds recognised by the sciences) does not in fact have the resources to do this.

My third and final example is John Dupré, who says:

To assert that there are real essences is, in part, to claim that there are fundamental properties that determine the existence and extensions of kinds that instantiate them. The existence of such properties would have profound metaphysical consequences. In particular it would imply that the existence of kinds of things was as much a matter of fact about the world as was the existence of particular things. Such kinds would be quite independent of our attempts to distinguish them, and their discovery would be an integral part of the agenda of science. The majority of contemporary usage takes such independent existence of kinds defined by real essences and awaiting scientific discovery as constituting the necessary and sufficient condition for the existence of a natural kind. Certainly, the existence of a natural kind ... will follow from the existence of a real essence. $(1993,62-3)$

While Dupré does not mention Kripke or Putnam by name here, KP is clearly the view he is describing. On that view, natural kinds are just those kinds that have 'independent existence', are 'defined by real essences' and await scientific discovery. So theoretical identities such as 'gold is the element with atomic number 79' are necessary (since having atomic number 79 is the 'real essence' of gold) and knowable only a posteriori (since it is a matter of scientific discovery what the real essence of gold is). He thus credits KP with 'profound metaphysical consequences'. One such alleged consequence, alluded to here, is that the essences of natural kinds - in effect, whatever appears on the right-hand side of a theoretical identification - are, always and everywhere, Lockean real essences; that is to say, underlying intrinsic features which causally explain manifest properties. Thus Dupré takes it that an evolutionary approach to taxonomy in biology is incompatible with the 'essentialism' of Kripke and Putnam $(1993,38)$. A second alleged consequence is the claim that kinds are 
'independent of our attempts to distinguish them'. Whatever exactly this means, it is a claim that Dupré clearly takes to be incompatible with his own 'promiscuous realism' and, in particular, with species pluralism.

The central contention of this chapter is that the claims made by Ellis, LaPorte and Dupré, amongst others, concerning the metaphysical consequences of KP are significantly overstated. KP does not, just by itself, deliver a metaphysically significant brand of necessity ('real' necessity). Nor, pace LaPorte, would it (if true) ward off the threat of incommensurability; nor, pace Dupré, would it establish the falsity of species pluralism.

My argument will turn on a fact that it is worth making explicit, namely that any prima facie plausible version of natural kind essentialism (of the sort that Ellis, Dupré and LaPorte are interested in) relies on a very significant extension of KP to the non-vernacular 'substantial' natural kind terms of physics, chemistry and (perhaps) biology. In other words, what goes for 'water' and 'gold' goes also for 'phosphorus trichloride', 'ununbium', 'Higgs boson', 'Coracias tibicen telonocua', and so on. ${ }^{6}$

Nigel Sabbarton-Leary and I argue elsewhere (2010b) that such an extension is not warranted. Moreover, as LaPorte's (2004) and Dupré's (1993) arguments against KP show, it is not even clear that KP really works even for the vernacular terms for which it was designed. (My beef with LaPorte and Dupré is not that there is something wrong with their anti-KP arguments; only that they overstate the clout of their opponent.) Nonetheless, I shall assume for the sake of the argument that KP does work for vernacular kind terms, and that the required extension to non-vernacular kind terms can, in principle, be made to work. But, I shall argue, the very moves that would be needed in order to make it work for non-vernacular kind terms render KP unable to perform the metaphysical wonders that have been claimed for it. So the view I have in my sights is not, strictly speaking, KP just by itself, but KP combined with the assumption just described: roughly, the view that KP holds for the kind terms of the sciences.

\footnotetext{
${ }^{6}$ Ellis himself holds on independent metaphysical grounds that there are no natural biological species kinds (see Ellis 2001, 167-70). But he does assume that KP holds for the natural substance kinds terms of physics and chemistry; indeed he also assumes that it holds for 'natural kinds' of process and property.
} 


\section{The $O K$-mechanism and 'nontrivial' essentialism}

Let's start with Nathan Salmon's account - drawing on unpublished work of Keith Donellan - of how Kripke and Putnam secure the necessary a posteriori status of 'water is $\mathrm{H}_{2} \mathrm{O}$ ', which he calls the 'OK-mechanism' (Salmon 2005, 166-7; sentences renumbered):

(1) It is necessarily the case that: something is a sample of water if and only if it is a sample of $d$ that (the same substance as this is a sample of).

(2) This (liquid sample) has the chemical structure $\mathrm{H}_{2} \mathrm{O}$.

(3) Being a sample of the same substance as something consists in having the same chemical structure.

Therefore,

(4) It is necessarily the case that: every sample of water has the chemical structure $\mathrm{H}_{2} \mathrm{O}$.

This argument, Salmon says, is 'intuitively valid' (though (3) needs further tinkering in order to make the argument genuinely modally valid; more on this below), and, since (at least) one of the premises, namely (2), is knowable only a posteriori, (4) can also only be known a posteriori. Thus we derive a necessary a posteriori theoretical identification.

Before proceeding, we need to pause briefly to consider the inadequacy of (3) as it stands. The most important problem for present purposes is that it only provides an intra-world condition on consubstantiality, whereas what's needed to make the argument modally valid is an inter-world condition. Salmon therefore replaces it with:

$\left(3^{*}\right) \quad[\mathrm{I}] \mathrm{f} x$ exists in $w_{1}$ and $y$ exists in $w_{2}$, and if furthermore $x$ is a sample in $w_{1}$ of the same substance that $y$ is a sample of in $w_{2}$, then whatever chemical 
structure $x$ has in $w_{1}, y$ has that same chemical structure in $w_{2}$, and vice versa. $(2005,179-80)^{7}$

Because it's easier on the eye, however, I shall continue to refer to (3), and take it as read that the same substance relation is to be conceived as an inter-world relation.

My interest in this section is in Salmon's charge that (3) has 'nontrivial essentialist import' $(2005,185)$. This has been noted by enemies of natural kind essentialism (e.g. Mumford 2005); but what, exactly, does this import amount to? I want to argue that while KP's essentialist import is indeed nontrivial in Salmon's very specific sense, it isn't highly nontrivial; in fact, it's something most contemporary metaphysicians wouldn't think twice about signing up to, and it falls a long way short of the kind of highly nontrivial essentialism embraced by natural kind essentialism.

Salmon regards (3) as enshrining 'nontrivial' essentialism because he contrasts it with 'trivial' essentialism. Thus:

Given that 'Hesperus' rigidly denotes the planet Venus, the identity sentence 'Hesperus is identical with Phosphorus' is necessary ... if and only if Venus is such that it could not fail to have the property of being identical with Phosphorus. Hence, using only some elementary modal semantics and the established fact that Hesperus is Phosphorus, we are able to derive from the theory of direct reference the result that the planet Venus has a certain essential property, namely the property of being Phosphorus. $(2005,82)$ This derived result, however, if it is a brand of essentialism at all, is a brand of essentialism of the most trivial and innocuous kind. It is not the deeply metaphysical sort of essentialism that has come under so much criticism. $(2005,83-4)$

Roughly speaking, the idea here is that being identical with Phosphorus is a pretty innocuous essential property for Venus to possess because it follows trivially from the fact that all identities are necessary, and that this 'trivial' form of essentialism is all

\footnotetext{
${ }^{7}$ Salmon deliberately replaces the necessary and sufficient conditions on consubstantiality implicit in 'consists in', in (3), with a merely necessary condition in $\left(3^{*}\right)$ (i.e. ( $\left.3^{*}\right)$ has 'if ... then', and not 'iff'), because sufficiency is irrelevant to the validity of the argument; see Salmon 2005, 179.
} 
that Kripke's semantics for proper names delivers. KP, by contrast - the claim that theoretical identities are necessary a posteriori - entails, and on Salmon's view entails because it presupposes, essentialism of 'deeply metaphysical sort'.

What is this 'deeply metaphysical sort' of essentialism? The answer is implicit in a footnote to the passage just quoted: 'Quine is the best known and most outspoken critic of essentialism' (2005, 84 n.4). Indeed so, on a certain understanding of 'essentialism', namely what Quine calls 'Aristotelian essentialism': the view that 'some of the attributes of a thing (quite independently of the language in which the thing is referred to, if at all) may be essential to the thing but others accidental' (Quine 1966, 175-6). Kripke similarly characterises essentialism as 'the belief in modality de re' $(1980,39)$. In other words, all that 'nontrivial essentialism' amounts to is a belief in de re modality, and/or the belief that there is a language-independent distinction to be drawn between the essential and accidental properties of a thing (or, in the case of natural kinds, kinds of thing).

Essentialism thus conceived is not, by the lights of contemporary metaphysics, a very strong thesis. ${ }^{8}$ This may be obvious to those readers who appeal to de re modality on a daily basis without considering themselves to be essentialists in any robust sense; but it is worth spelling out. We can shed a little more light on the matter by drawing an analogy with essentialism about individuals. L. A. Paul (2006) draws a useful distinction between 'deep' and 'shallow' essentialism. She says:

Deep essentialists take the (nontrivial) essential properties of an object to determine its nature - such properties give sense to the idea that an object has a unique and distinctive character, and make it the case that an object has to be a certain way in order for it to be at all ... Intuitively, on the deep essentialist picture, an ordinary object has essential properties, and it must have its essential properties in order for it to exist. On this view, objects' essential properties are absolute, i.e., are not determined by contexts of describing (or thinking, etc.) about the object, and truths about such properties are absolute truths. Shallow essentialists oppose deep essentialists: they reject the view that objects can be said to have essential properties independently of contexts of

\footnotetext{
${ }^{8}$ Indeed, Kit Fine (1994) argues that the resources of de re modality are insufficient for accounting for essences; on Fine's view, then, 'nontrivial essentialism' in Salmon's sense isn't really 'essentialism' at all.
} 
description or evaluation, and so substitute context-dependent truths for the deep essentialist's context-independent ones. $(2006,333)$

So, for example, let's agree that it is part of my essence that I am human (let's say): I could not have existed without being human. By contrast, having long hair is not part of my essence, since I could still have existed (and once did exist) without having long hair. According to the deep essentialist, the former fact about my essence in no way depends on how I am described, or the context within which my essence is being discussed. According to the shallow essentialist, by contrast, there are no absolute, context-independent facts about essences. David Lewis is a prime example of a shallow essentialist: for Lewis, ' $a$ has property $F$ essentially' amounts to ' $a$ has property $F$ in all possible worlds in which $a$ exists', which in turn amounts to 'all of $a$ 's counterparts have $F$ '. So far, we don't have anything that a deep essentialist need disagree with (though of course some do, e.g. because they reject counterpart theory). The crucial move is the further claim that the counterpart relation - what makes an inhabitant of another possible world a counterpart of $m e$, say - is context-dependent. Lewis asks whether there is a 'settled answer, fixed once and for all, about what is true concerning a certain individual according to a certain (genuine or ersatz) world' $(1986,198)$. And his answer is an emphatic 'no':

there is a great range of cases in which there is no determinate right answer to questions about representations de re, and therefore no right answer to questions about modality or counterfactuals de re. Could Hubert Humphrey have been an angel? A human born to different parents? A robot? A clever donkey that talks? An ordinary donkey? A poached egg? Given some contextual guidance, these questions should have sensible answers. There are ways of representing whereby some worlds represent him as an angel, there are ways of representing whereby none do. $(1986,251)$

Shallow essentialism is 'shallow', then, because it regards essence claims as entirely legitimate - it takes objects to have essences - while denying that they have essences in any 'absolute, context-independent sense' (Paul 2006, 345). We can agree, in ordinary conversational contexts, that I am essentially human, but that is not a 'deep' fact about me: in a different context, where the bar for counterparthood is set 
lower, I am only accidentally human (I might have been a robot, say, or an angel). So while the shallow essentialist agrees with the deep essentialist that (in ordinary contexts) $I$ could not have existed without being human, this is not really a very interesting fact about me: it does not reveal a deep metaphysical truth about the conditions for my existence, since we can change the essential facts by switching context.

What is important about shallow essentialism for present purposes is that it is 'essentialism' in a very innocuous sense. It is 'nontrivial' in Salmon's sense because it is a version of the view that the accidental/essential distinction is 'independent of the language in which the thing is referred to'. Lewis's view, for example, is not that whether some non-human in another possible world is a counterpart of me is determined by how I am referred to. In ordinary contexts referring to me as 'the object, part of which is currently in contact with the " $a$ " key on the laptop' doesn't make it the case that I am only accidentally human; the question whether $I$ am essentially human is a de re modal question about me, and not a de dicto question about the necessity or contingency of the sentence 'the object partly in contact with the 'a' key is human'. ${ }^{9}$ Nonetheless, Lewis's essentialism is 'shallow' because it this de re question about me cannot be settled independently of context: it will only have a 'sensible answer' given 'some contextual guidance'.

For the purposes of this paper, the important question is whether, consistent with KP, we can import something like the shallow/deep distinction into the case of natural kinds. If we can do this, and if shallow essentialism is consistent with KP, then it will turn out that KP is consistent with metaphysical views that only just barely deserve to be called 'essentialist'. It will thus become clear that the kinds of metaphysical work that the authors discussed in $\$ 2$ claim on behalf of KP cannot, in fact, be done by KP just by itself. ${ }^{10}$ If that work is to be done at all, it must be done by independent metaphysical assumptions that need to be argued for on independent grounds.

\footnotetext{
${ }^{9}$ I take it Salmon's view is that 'Venus is essentially identical to Phosphorus' is also a de re modal fact but is 'innocuous' because being identical to Phosphorus doesn't count as a genuine attribute.

10 As Lewis himself says: 'The true-hearted essentialist might well think me a false friend, a Quinean sceptic in essentialist's clothing' $(1983,42)$.
} 
In relation to Salmon, the basic point is this. Salmon is right that if we are to generate necessary a posteriori truths such as 'water is $\mathrm{H}_{2} \mathrm{O}$ ', 'nontrivial essentialism' must be assumed. So KP does indeed enshrine an independent metaphysical assumption. But that assumption is, by the lights of most contemporary metaphysicians, still pretty trivial; in other words, it is shallow - although we will not be in a position to see exactly what 'shallowness' amounts to in the case of natural kind essentialism until $\S 8$.

\section{Carving nature across its joints}

Natural kinds, as is often remarked, are supposed to 'carve nature at its joints'. It's not always very clear what 'carving nature at its joints' is supposed to amount to, but I take it the basic idea is that there is one, unique way to carve out the natural kinds. Thus, first, artificial or gerrymandered kinds (emerose, say, or football, or thing bigger than the average car) 'crosscut' nature's joints, a bit like a bad butcher hacking through the carcass of a cow and ending up with thin rib plus a bit of brisket, or most of the rump and a bit of sirloin. Second, higher-level kinds that crosscut each other are ruled out, so that (for example) if two chemical substances are of the same higher-level kind (e.g. chlorine and iodine are both halogens), there is no other higher-level kind that has one as a member but not the other. Stretching the analogy somewhat, the top and bottom sirloin are both sirloin cuts, but there is no cut that has one not but both of these lower-level cuts as a part (say, top sirloin plus rump). Third, which way the joints are 'correctly' carved is absolute. There isn't (let's suppose) the 'right' way to carve up a cow carcass for the French, and another for the British, and so on, with no fact of the matter about which way really carves it up 'correctly'. Similarly, there isn't a 'right' way to carve up nature from the perspective of Newtonian physics (or one 'species concept' in biology) and a 'right' way to carve it up from the perspective of relativistic physics (or a different species concept), with no fact of the matter about which way really carves it up 'correctly'.

In view of the fact that natural kinds are commonly supposed to carve nature at its joints, one might hold that the thesis that there is one unique way in which to carve it up is an a priori constraint on any theory of natural kinds, properly so-called. But, as we shall see, some apparently entirely legitimate kind terms of the sciences $d o$ crosscut. In response to this fact, one might dig one's heels in and insist that a truly natural kind obeys the hierarchy thesis. Or one might (as Ian Hacking (2007) does) 
cite the existence of crosscutting kinds (again, in the second sense) as one reason to abandon talk of natural kinds all together. The dominant view, however, is that, however unruly talk of natural kinds may have become in recent years, there is, at the very least, an intuitive distinction in nature between arbitrary and gerrymandered kinds on the one hand and kinds such as electron, tiger, and oxygen; and that, however strongly participants in the debate may disagree on the extension of "natural kind', the notion of a natural kind is still worth holding on to. So we should not start out - or at least not without good reason - with the assumption that any natural kind worthy of the name will not crosscut in any of the above senses.

As we saw in $\S 2$, defenders and enemies of KP alike have claimed that KP rules out crosscutting of one or other of the types just identified. In other words, they claim that, if KP holds, we do have good reason to hold that natural kinds do not crosscut, in at least one sense of 'crosscut'. Thus Dupré takes KP to be incompatible with species pluralism, and both Putnam and LaPorte take it to rule out Kuhnian relativism. These claims, I shall argue, are mistaken.

In the rest of this section, I shall distinguish between four different ways in which someone might hold that natural kinds can crosscut (building on Tobin 2010, which distinguishes between 'intrataxonomic' and 'intertaxonomic' crosscutting), as follows:

Artificial crosscutting: Artificial kinds are, of course, easy to come by (house, blue car, lampshade); and, one might think, equally easy to dismiss as candidates for natural kinds. I shall not attempt to argue that KP fails to rule out even artificial crosscutting, though it should be noted that Putnam himself argues that kinds such as pencil and paediatrician count as 'natural kinds' - for example, that it is necessary $a$ posteriori that pencils are artefacts $(1975,242-3)$. If Putnam is right that KP is consistent with the necessary a posteriori status of 'pencils are artefacts', then of course any account of the naturalness of truly natural kinds (i.e. kinds that do not include pencil) is going to have to deploy independent metaphysical assumptions to get the job done.

Intrataxonomic crosscutting is incompatible with the hierarchy thesis. There are, in fact, several different versions of 'the' hierarchy thesis (see Tobin 2010, 180-5). One might hold that for any two natural kinds $K 1$ and $K 2$, if any object or substance $o$ is a member of both kinds, then either $K 1$ is a sub-kind of $K 2$, or vice versa. Ellis subscribes to a weaker thesis: he requires only that 'if anything belongs to two 
different natural kinds, these natural kinds must both be species of some common genus' $(2001,20)$ (a requirement he takes to be 'satisfied trivially if one of the two kinds is a species of the other' (ibid.)).

Intrataxonomic crosscutting is crosscutting within a single classificatory framework (hence 'intra'); Emma Tobin argues that enzyme and protein constitute a clear example (2010, §3, see also Khalidi 1998 and Hacking 2007, 214). This is a (putative) case of intrataxonomic crosscutting because there is no disagreement within chemistry about what it takes for something to be an enzyme or a protein; rather, these kinds crosscut in the sense that they fail to fit either the stronger or the weaker hierarchical theses described above. The categories enzyme and protein crosscut in that not all enzymes are proteins and not all proteins are enzymes. This is incompatible with both the stronger hierarchy thesis (since enzyme is not a sub-kind of protein, and nor is protein a sub-kind of protein) and the weaker one (since there is no chemical genus of which both enzyme and protein are species).

It may seem obvious that KP does not entail the hierarchy thesis, taken in either of the above senses. In fact, however - in the case of biological kinds - a hierarchy thesis is typically built in to some ways of specifying the biological-kind analogue of premise (3) in the $O K$-mechanism, as we shall see in $\S 5$.

Intertaxonomic crosscutting, as Tobin defines it, is cutting across different classificatory frameworks - the rough equivalent of the French vs. British schools of butchery. The case Tobin has in mind is species pluralism. There is a smorgasbord of different 'species concepts' from which to choose - in particular, morphological (based on shared characteristics), biological (based on reproductive isolation), and phylogenetic (based on genealogy). Dupré, following Kitcher (1984), argues for a 'radically pluralistic conception of species' (1993, 50): ‘both historical (evolutionary) and structural (or functional) inquiries should be accorded equal weight in biology, and ... they may require different classificatory schemes' $(1993,50-1)$. To accept species pluralism is thus to endorse intertaxonomic crosscutting. As we have seen, Dupré takes species pluralism (and so, presumably, intertaxonomic crosscutting generally) to be incompatible with KP.

Interparadigm crosscutting: Let's define interparadigm crosscutting as the thesis that the theoretical terms of successive scientific paradigms are incommensurable, so that there is no fact of the matter about which of the incommensurable classificatory systems carves nature up 'correctly'. Thus Kuhn says, '[a]t the very least, as a result 
of discovering oxygen, Lavoisier saw nature differently. And in the absence of some recourse to that hypothetical fixed nature that he "saw differently", the principle of economy will urge us to say that after discovering oxygen Lavoisier worked in a different world' $(1970,118) .{ }^{11}$ As we've seen, LaPorte explicitly takes KP to rule out interparadigm crosscutting.

In $\S \S 5-7$, I shall argue that intrataxonomic (§5), intertaxonomic (§6) and interparadigm crosscutting $(\S 7)$ are all compatible with KP, even granted its nontrivial essentialist premise.

\section{Intrataxonomic crosscutting}

Intrataxonomic crosscutting is crosscutting that is enshrined within a single theoretical framework (as with - according to Tobin - enzyme and protein). I'll argue for the compatibility of intrataxonomic crosscutting with KP via a slightly circuitous route, and begin by recalling premise (3) of the $O K$-mechanism.

Let's start, then, with what Putnam calls the 'same-liquid relation' or, more broadly but similarly, the same-substance relation. In what does this relation consist? Salmon's answer, on behalf of defenders of KP, is: having the same chemical structure (as in (3)); and defenders of KP do indeed endorse (3), or something similar. Thus Putnam himself says: 'we can understand the relation same $_{L} \ldots$ as a cross-world relation by understanding it so that a liquid in world $W_{l}$ which has the same important physical properties (in $W_{1}$ ) that a liquid in $W_{2}$ possesses (in $W_{2}$ ) bears $\operatorname{same}_{L}$ to the latter liquid' $(1975,232)$. And he takes these 'important physical properties' to be 'the microstructure of water' (ibid.). Kripke is rather less forthcoming, saying only that 'science attempts, by investigating basic structural traits, to find the nature, and thus the essence (in the philosophical sense) of the kind' $(1980,138)$; so for Kripke the same substance relation is determined by shared 'basic structural traits'.

Relatedly, Scott Soames says:

\footnotetext{
${ }^{11}$ In fact, 'crosscutting' is perhaps a little misleading, because it suggests that there is such a thing as 'nature' that is differently carved by different theories, when Kuhn's stated position at least in the above quotation and some other places - is that there is no such thing. On the other hand, he later describes his view as 'a sort of post-Darwinian Kantianism' $(1990,12)$, which makes 'crosscutting' seem a little more appropriate, in that it suggests that there is indeed something - namely the noumenal realm - that incommensurable theories carve up in different ways.
} 
The term 'water' is to designate the unique substance of which (nearly) all members of the class of its paradigmatic samples are instances. Substances are explanatory kinds instances of which share the same basic physical constitution, which in turn explains their most salient characteristics - in the case of water-samples, the fact that they boil and freeze at certain temperatures, that they are clear, potable, and necessary to life, etc. Hence, the predicate 'is water' will apply (at a world-state) to precisely those quantities that have the physical constitution which, at the actual world-state, explains the salient features of (nearly) all paradigmatic water-samples. $(2007, * *)$

For Soames, then, the same-substance relation is determined by a shared 'basic physical constitution' that explains the 'most salient characteristics' of samples of the liquid or substance.

The problem I want to raise is best seen by considering a dispute between LaPorte and Alexander Bird over the issue of whether or not, prior to scientific investigation, the reference of 'water' was indeterminate, as LaPorte claims. LaPorte presents a thought experiment involving 'Deuterium Earth' (2004, 104-8). We are asked to imagine that inhabitants of a distant planet (DE) invite Earthlings for a visit, and Earthlings discover that, while the stuff flowing in the rivers and lakes of DE is a lot like water (it is certainly watery stuff), it has many different properties. For example, it is poisonous to animals brought to DE by the Earthlings, it melts and boils at different temperatures, and has been used by Deuterium Earthlings to create a powerful explosive weapon. As you might have guessed, the mysterious substance turns out to be $\mathrm{D}_{2} \mathrm{O}$. (Deuterium is an isotope of hydrogen, so $\mathrm{D}_{2} \mathrm{O}$ is a species of $\mathrm{H}_{2} \mathrm{O}$.) In the light of the many differences between $\mathrm{D}_{2} \mathrm{O}$ and the watery stuff here on Earth, the Earthling scientists come to the view that $\mathrm{D}_{2} \mathrm{O}$ is not water. LaPorte argues that our imaginary Earthling scientists have not made any mistake in refusing to classify $\mathrm{D}_{2} \mathrm{O}$ as water, and hence that actual scientists might, without error, have counted $\mathrm{D}_{2} \mathrm{O}$ as falling outside the extension of 'water'. Hence 'water is $\mathrm{H}_{2} \mathrm{O}$ ', while necessary, is not discovered to be true but stipulated to be true, and so is not $a$ posteriori.

In a later paper, LaPorte notes that ' $\mathrm{D}_{2} \mathrm{O}$ is a form of $\mathrm{H}_{2} \mathrm{O}$ with certain salient properties, that distinguish it from ordinary $\mathrm{H}_{2} \mathrm{O}$ : drinking it will not sustain our biological processes, for example. $\mathrm{D}_{2} \mathrm{O}$ behaves differently than ordinary $\mathrm{H}_{2} \mathrm{O}$ in 
nuclear reactions, its ability to absorb radiation ..., and across a range of other matters' $(2010,107)$. Hence - again - scientists might, without error, have counted $\mathrm{D}_{2} \mathrm{O}$ as falling outside the extension of 'water'. Bird responds to LaPorte by appealing to the 'division of linguistic labour among scientists, such that it is the job of a particular subset of scientists to determine the facts concerning particular sorts of natural kinds ... in the light of this, it will be chemical facts that determine the identity of substances' $(2010,127)$. And he claims that the relevant 'chemical facts' (structure, reactions, qualitative chemical properties, and so on) 'class $\mathrm{D}_{2} \mathrm{O}$ with other kinds of $\mathrm{H}_{2} \mathrm{O}$ ' (ibid.). He is unmoved by the fact that, for example, pure $\mathrm{D}_{2} \mathrm{O}$ is poisonous for many organisms and can be used in making powerful explosives, since 'these reasons [for not classifying $\mathrm{D}_{2} \mathrm{O}$ as water] come from outside chemistry' and so 'are not pertinent to the science whose job it is to investigate the nature of and to classify water' $(2010,128)$.

Since my aim is to uncover the consequences of KP and not to question its truth, let's grant that Bird's response succeeds. It turns, in effect, on the claim that it is the specific job of chemists to determine the nature of the same substance relation. Indeed, Bird quotes Linus Pauling here: 'The different kinds of matter are called substances. Chemistry is the science of substances - their structure, their properties, and the reactions that change them into other substances (Pauling 1970, 1). ${ }^{12}$

The problem is that Bird's response, if it is to succeed, makes the determination of the same-NK relation hostage to one of the very kinds of crosscutting that one might have hoped that KP would rule out, namely intrataxonomic crosscutting, as exemplified by chemical kinds such as protein and enzyme. There are, of course, no 'folk' terms associated with these kinds; nonetheless, the terms were coined by scientists (in the eighteenth and nineteenth centuries) well before their 'essences' were discovered; correspondingly, experts could (fallibly) distinguish a protein from a non-protein, and an enzyme from a non-enzyme. Hence the terms 'protein' and 'enzyme' would seem ripe for delivering necessary a posteriori

\footnotetext{
${ }^{12}$ It's worth pointing out that Bird's conception of the division of linguistic labour is considerably stronger than Putnam's original conception (1975, 227-9). For Putnam, the linguistic work that 'experts' perform is (in the context of natural kinds) that of distinguishing one kind from another: gold from fool's gold, elms from beeches, aluminium from molybdenum, and so on. For Putnam, then, the division of linguistic labour has nothing to do with the discovery of essences, or, equivalently, the discovery of the nature of the samesubstance relation.
} 
theoretical identities of the form 'a protein is ...' and 'an enzyme is ...'; in which case, we have intrataxonomic crosscutting, consistent with KP.

One might object that the kind enzyme fails to satisfy the requirements of the same-NK relation. Enzymes are characterised in terms of the role they play in chemical reactions (they are catalysts), and do not have any unified underlying nature: most are globular proteins, but some are RNA molecules. But now the question is: why should we think that members of chemical kinds must share an underlying nature, in a way that would rule out enzyme from counting as a natural chemical kind? If, as Bird claims, the division of linguistic labour requires us to defer to chemists to work out what the essence of a natural kind is, and if chemists recognise enzyme as a legitimate kind (which they do), on what grounds could we rule out enzyme as counting as a genuine, crosscutting chemical kind? Of course, as we have seen, many natural kind essentialists claim that the same- $N K$ relation - or at any rate the samesubstance relation - is a matter of sameness of structure or constitution. But this - as the case of enzymes makes clear - is not a requirement that is delivered by chemistry itself.

It might be objected that I have here slipped from talking about the samesubstance relation to talking about the same chemical kind relation, and that there is an important distinction between the two: albumin and the hairpin ribozyme are both enzymes, but they are not the same substance. So if we are concerned with the samesubstance relation, as Bird is, we do not have a counter-example to the hierarchy requirement that bans intrataxonomic crosscutting. Well, grant that there is an ordinary, commonsense notion of 'substance', according to which albumin and the hairpin ribozyme are not the same substance. Nonetheless, there is $a$ chemical kind of which they are both members, viz, enzyme. And if KP is to be extended in such a way as to deliver the natural kinds recognised by the sciences, then it simply cannot be restricted a priori to just those kinds that we pre-theoretically recognise as substance kinds. In other words, if we restrict our categories - the ' $N K$ ' in 'same $N K$ ' - to the vernacular (substance, fruit, liquid, and so on), KP will deliver only a tiny fraction of the necessary a posteriori theoretical identities required by natural kind essentialism.

This last point is important because it raises the issue with which the rest of this paper will be concerned. Recall premise (1) of the $O K$-mechanism: 'It is necessarily the case that: something is a sample of water if and only if it is a sample of dthat (the same substance as this is a sample of)'. (1) thus appeals to the same- 
substance relation in its formulation. Putnam notes, in the cases of same-liquid, samefruit, and so on, that 'liquid' and 'fruit' are 'markers' that 'may be explicit or implicit' $(1975,229)$. In the case of albumin and the hairpin ribozyme, what will the relevant 'marker' be?

We have a choice here. We could say that it is still the same-substance relation, where 'substance' is now no longer the pre-theoretical notion but a term of art from chemistry (though of course we would then have to distinguish different notions of 'substance' in order to distinguish those substances such as water and gold, for which (3) is true, and those 'substances' such as enzymes and proteins, for which some suitable substitute for (3) is true). Or we could keep the pre-theoretical notion of 'substance' and admit that it doesn't capture all the chemical kinds. In that case, we will in addition need to recognise not only the kinds enzyme and protein, but also something like same-chemical-kind in order to get KP off the ground for enzymes and proteins. Thus, for example, a suitable candidate for an analogue of (1) might be: 'It is necessarily the case that: something is an enzyme if and only if it is of the same chemical kind as this is a sample of'.

Either way, we will have to accept that deference to the taxonomy of chemistry is required in order to generate premise (1), for what counts as a chemical kind is, of course, a matter for chemistry to determine: it is simply not open to us, pretheoretically, to determine what does and does not count as a chemical kind. This point will, I hope, become clearer in the next section.

\section{Intertaxonomic crosscutting}

Let's move on to intertaxonomic crosscutting, as exemplified by species pluralism. Here we have to move away from the same substance relation, since of course biological kinds are not kinds of substance. What should we replace it with in the biological version of the $O K$-mechanism? As we have seen, Putnam takes the relevant relation to be the same-animal relation. We can think of same-animal as on a par with same-substance: the concept of an animal is a commonsense, pre-theoretical concept. Of course, Putnam says that the same-liquid relation is a 'theoretical relation: whether something is or is not the same liquid as this may take an indeterminate amount of scientific investigation to determine' $(1975,225)$. Presumably he takes the same to hold for same-animal too. But that is not incompatible with saying that 'animal' is a pre-theoretical concept; someone with no knowledge of biology can point to two pigs 
and say 'this is the same animal as that' without having any idea what the sameanimal relation consists in.

Well, since same-animal is allegedly a theoretical relation, in Putnam's sense, what, according to a biologist, does it consist in? The answer will surely be a shrug of the shoulders, since the question is simply not framed in a way that makes it answerable from the perspective of biological classification. Take elephants, for example. Is this (African) elephant the same animal as that (Asian) elephant? Well, the African and Asian elephants are members of different genera (Loxodonta and Elephas) of the same family (Elephantidae). So if by 'same animal' we mean 'same species' or 'same genus', the answer is 'no'; but if we mean 'same family' the answer is yes. It's pretty obvious that on our pre-theoretical understanding of 'same animal', whatever that is, it does not mean either of those things. So biology must do more than merely determine whether something is or is not the same animal as this; it must also, if KP is to have any connection with the natural kinds recognised by biology, supply the categories that fill in the ' $N K$ ' in 'same $N K$ ': not, as it turns out, same animal, but same subspecies, same species, same genus, and so on.

In fact, this point is implicit in more recent attempts to get $\mathrm{KP}$ off the ground for biological kinds; in particular, both Soames and Salmon replace the same-animal relation with the same-species relation. Thus Soames says:

The term 'tiger' is to designate the species of animal of which (nearly) all members of the class of its paradigmatic samples are instances. Hence, the predicate 'is a tiger' will apply (at a world-state) to precisely those individuals that are members of the species of which (nearly) all paradigmatic tiger-samples are actually members. $(2007, * *)$

Note that Soames does not tell us what the same-species relation consists in; while he is happy to assert that 'substances are explanatory kinds instances of which share the same basic physical constitution, which in turn explains their most salient characteristics' $\left(2007,{ }^{* *}\right)$, he says nothing at all about what sameness of species might amount to.

Salmon's own version of the $O K$-mechanism for tigers, on behalf of the defender of KP, runs as follows: 
(1') It is necessarily the case that: something is a tiger if and only if it is a member of $d$ that (the same species that this is a member of).

$\left(2^{\prime}\right) \quad$ This has the biological class property of being a mammal.

(3') Being a member of the same species as something consists (in part) in being a member of the same biological class.

Therefore

$\left(4^{\prime}\right) \quad$ It is necessarily the case that: all tigers are mammals.

So Salmon, like Soames, fixes on the same-species relation. Unlike Soames, he does say something about the necessary conditions for the relation to hold, viz, in effect, that species are part of a hierarchical taxonomic structure: in order for two animals to be members of the same species, they must both equally be members of the same higher-level biological class - in the case of tigers, this is Mammalia.

Now, Salmon's primary interest is in whether or not ( $\left.3^{\prime}\right)$ (or rather, the interworld version thereof) can be known wholly a posteriori; and his conclusion is that it cannot, roughly because it is unclear how empirical investigation might deliver knowledge of inter-world same-NK relations, even if it delivers knowledge of intraworld same-NK relations. My interest is different: my claim is that $\left(3^{\prime}\right)-$ and indeed $\left(1^{\prime}\right)$ - cannot so much as be stated without deploying the (or a) classificatory framework of biology. We need to appeal to that framework in order to have at our disposal the appropriate 'marker' or category $N K$ in 'the same $N K$ that this is a member of'. In other words, biological science, and the classificatory framework(s) it deploys, is needed not merely to tell us what the same-species relation consists in (or has as a necessary condition); it is needed to provide us with the very concept of species required for the $O K$-mechanism to get off the ground. Or at least it does if KP is to work out for the natural kind terms recognized by biology.

Why is this so? Simply because species is not (or at least is not, in the sense required for the KP to do the work it is supposed to do) a pre-theoretical notion. The pre-theoretical notion of a species is simply the notion of a kind (or perhaps the notion of a sub-kind, as in ' $x$ is a species of $y$ ', where $y$ is a higher-order kind of which $x$ is a sub-kind); and that, as we saw in the case of same-animal, is not good enough. For we need a substitute for ' $N K$ ' in 'same $N K$ ' - that is, we need a category - that is 
sufficiently fine-grained to yield a determinate answer to the question, "is this the same $N K$ as that?' Without that, no determinate kind has been identified, such that the essence of that kind can be established. And the notion of species that is sufficiently fine-grained to play that role is not the ordinary, pre-theoretic concept of species, but the biological concept of species, which occupies a determinate level (between genus and subspecies) in biological taxonomy. Moreover, species will not deliver all the required necessary a posteriori truths we need. We need also to be able to run the $O K$ mechanism for elephants, for example, so that our elephant version of the $O K$ mechanism runs: 'It is necessarily the case that: something is an elephant if and only if it is a member of dthat (the same ... that this is a member of), where the blank can only be filled in by 'family'. So, again, we need to appeal to the classificatory framework of biology in order to get KP off the ground.

We are now in a position to see that KP and species pluralism are compatible, and hence that KP is compatible with intertaxonomic crosscutting. By way of a foil, consider why someone might be inclined to think that the two are not compatible. In order to deliver necessary a posteriori theoretical identities of the form 'substance $S$ is ...' ('gold is the element with atomic number 79'), or 'all $T$ s are ...' ('all tigers are ..., where the blanks are filled in with a specification of the essence of, or a necessary condition on, tigerhood), where ' $S$ ' and ' $T$ ' are vernacular kind terms, it must surely be the case that the vernacular term designates one substance or species or whatever: a single natural kind. For recall premise (1') of the $O K$-mechanism that generates the necessary a posteriority of 'all tigers are mammals': it is necessarily true that: something is a tiger if and only if it is a member of the same species that this is a member of. But if species pluralism were true, there would be no such thing as the, unique, same species relation. Rather there would be, say, the same species $M$ relation, the same $\operatorname{species}_{B}$ relation, and the same species $P$ relation, corresponding to the morphological, biological and phylogenetic conceptions of species respectively. Hence, one might argue, 'something is a tiger if and only if it is a member of the same species that this is a member of' would, if species pluralism were true, simply be indeterminate in truth-value (or perhaps false), and so would not be necessarily true. Hence (1') would be false and the $O K$-mechanism couldn't get of the ground.

Unfortunately, this defence of the claim that species pluralism is incompatible with KP fails in the face of the claim defended above, that appeal to the classificatory framework of biology is required in order to furnish us with the categories that can 
replace ' $N K$ ' in 'same $N K$ '. If that claim is right, then the correct way to run the $O K$ mechanism is not to start out with (1') itself, since this deploys the vernacular or nearvernacular term, 'same species'. Rather, we must fill in the blank in 'same ... as this is a member of' by appealing to the appropriate category, as enshrined in the 'correct' classificatory framework for biology. Species pluralism, if true, entails that there is not just one same species relation, for example, but several: same species ${ }_{M}$, same

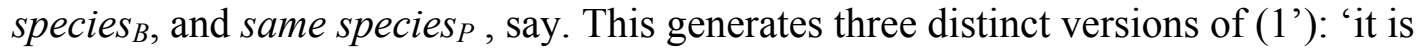
necessarily true that: something is a tiger if and only if it is a member of the same species $_{M}$ that this is a member of' is one; replacing 'same species ${ }_{M}$ ' with 'species ${ }_{B}$ ' and 'speciesp' delivers the other two versions. And now we can run the $O K$ mechanism and end up with our necessary a posteriori truth.

My conclusion, then, is that - pace Dupré - KP is compatible with species pluralism. In case this seems implausible from the perspective of KP, it is worth reiterating that the kind of line defended above is required by KP in any case, even if species pluralism is false, if KP is to apply to biological kinds at all. Subspecies, species, genus, and so on are no part of pre-theoretical commonsense classification. Pre-theoretical classification arguably does involve some degree of hierarchy: we might recognise, for instance, that a tabby cat and a Manx cat are both kinds of domestic moggy, and that the domestic moggy, tigers and lions are all kinds of cat. But we have no pre-theoretic grasp of where the levels of biological classification lie: no pre-theoretical grasp of whether, say, tabby and Manx are species or sub-species, or whether elephant is a genus of a family. It is not currently known, even by biologists, whether African forest elephant is a subspecies of the African elephant, or whether the African forest and bush elephants are distinct species. So the defender of $\mathrm{KP}$ must in any case take it that we defer to biologists to determine which biological kind (species, genus, etc.) is to replace the placeholder ' $N K$ ' in 'same $N K$ '.

\section{Interparadigm crosscutting}

Finally, let's consider the most radical kind of crosscutting: interparadigm crosscutting. As I noted earlier, Putnam (1975) explicitly takes his version of KP to undercut Kuhnian relativism by securing stability of reference across theory change. As we have seen, LaPorte $(2004,2010)$ agrees, but seeks to undermine KP: he argues that a broadly causal story about reference-fixing is consistent with a degree of 'vagueness' of reference at the pre-scientific stage at which reference (of, say, 'water' 
or 'gold') is fixed by the folk; the meaning of the term is then precisified by scientists at the point at which a decision needs to be made. Hence scientists do not discover the essence of (say) water, but rather stipulate a new meaning.

LaPorte's basic claim, then, is that a broadly causal theory of reference need not deliver necessary a posteriori theoretical identities: according to LaPorte, in effect, premise (3) in the $O K$-mechanism is secured by stipulation rather than discovery. ${ }^{13}$ In contrast to LaPorte, I want to argue that, even if we grant the necessary a posteriori status of theoretical identities, we do not necessarily secure referential stability: nothing in KP, just by itself, rules out interparadigm crosscutting, which I defined in $\$ 4$ as the thesis that the theoretical terms of successive scientific paradigms are incommensurable, so that there is no fact of the matter about which of the incommensurable classificatory systems carves nature up 'correctly'.

Putnam's basic thought is that referential stability is secured by semantic externalism. If we abandon the view that the reference of 'gold' is fixed by a description, then the change in description that goes along with a change in theory need not amount to any change in reference. When we move from thinking of gold as (say) a yellow, malleable metal to being the element with atomic number 79 , there is no shift in meaning of the term 'gold', since the meaning of 'gold' is just its reference, and that remains constant: we're still referring to the same substance, we just take a different view of what it's like. More precisely, in this case we move from not knowing the essence of gold but only knowing some criteria by which gold can reasonably reliably be distinguished from non-gold to knowing its essence (or at least having a reasonable but nonetheless fallible belief about its essence).

It might seem obvious that all this is incompatible with interparadigm crosscutting. After all, if the meaning of 'gold' is just its reference, then of course changes in theory cannot change the reference of 'gold': gold remains the same substance, whatever our theories happen to say about it. But recall the basic point developed so far. If the semantic category of natural kind terms is to have any systematic connection with the kinds recognised by the sciences, deference to science cannot amount merely to the discovery of what it is to stand in the same-NK relation, where ' $N K$ ' is some pre-scientific category (substance, animal, etc.). Instead, science

\footnotetext{
${ }^{13}$ Robin Hendry (2010) argues that LaPorte's claim about 'water' doesn't generalise, and that whether a given term fits the model of KP must be decided on a case-by-case basis; in particular, he argues that 'oxygen' does fit the KP model.
} 
must also be deferred to when it comes to specifying the value of ' $N K$ ': scientific enquiry reveals that the relevant relations are not merely same substance, same animal, and so on, but also same kind of subatomic particle, same chemical kind, same genus, and so on - and, if species pluralism is true, also same species same $\operatorname{species}_{B}$, and same $\operatorname{species}_{P}$, or whatever.

The problem now is that, with this degree of linguistic deference to science on the table, it is far from obvious that the resources of KP, just by themselves, are sufficient to ward off the threat of relativism. Putnam's anti-relativist move depends on the assumption that gold in 1973 is the same substance as gold in $437 \mathrm{BC}$; all that's changed is the extent of our knowledge of its nature. In other words, it depends on the claim that there is a theory-neutral sense of same substance, such that changes in theory are powerless to change what it is for one thing to be the same substance as another. We can grant that there is indeed a set of pre-theoretical categories (substance, liquid, animal, fruit) that resist referential instability. But, as we have seen, such categories on their own will not get the defender of KP what they need, in the context of marrying up the semantic category of natural kind terms with the natural kinds recognised by science. For that, we need distinctively theoretical categories. And of course such categories are apt to change as the theories within which they are categories are replaced by different theories with different taxonomic structures.

The defender of Kuhnian relativism can, I claim, hold that such changes deliver genuine changes in reference of the kind terms involved, consistent with KP. Take chemistry. As things currently stand, in a period of what Kuhn calls 'normal science', let's suppose that KP works out as normal. Some new kind of stuff is discovered, given a name, and its essence is then revealed by chemical analysis, delivering us a necessary a posteriori theoretical identity. All well and good. But this presupposes a classificatory framework that comes from chemistry itself: same element, same chemical kind, same organic compound, and so on. Without that classificatory framework, there is no way to fill the placeholder ' $N K$ ' in 'same-NK' that can make sense of the vast range of natural kinds that chemistry tells us there are.

Now imagine some seismic change in the classificatory framework of chemistry. The new framework, let us imagine, simply does not recognise the categories element, catalyst, organic compound, and so on at all, and replaces them with new categories that carve up the terrain in very different ways. More generally, 
the category chemical kind now incorporates very different subspecies. So, for example, we can no longer say truthfully, pointing at two samples of proteins, that they are of the same chemical kind, because the new framework recognises no kind of which both our samples are members. But we can still, from within the new framework, perfectly happily go about the business of identifying substances or objects and discovering the essences of the kinds to which they belong (although of course this project will not be fully distinct from the project of discovering which kinds they belong to).

The Kuhnian relativist will characterise this situation as one in which the natural kinds have changed: it is not that the same kind of substance or entity has been discovered to have different essence to the one we thought it had; rather, the old kind has genuinely ceased to exist, and has been replaced with another kind. After all, if it is the same kind of substance or entity, which kind of substance or entity, exactly, would that be? Not the same chemical kind, because the old chemical kinds are no longer a part of the classificatory framework of chemistry. Albumin and rennin would not both be enzymes, and hydrogen and deuterium would not both be isotopes of the same element, because such categories, we are imagining, have ceased to apply.

My claim here is not that relativism is a defensible position. It is rather that relativism - which is to say, interparadigm crosscutting - is consistent with KP: we simply relativise the same- $N K$ relations to the classificatory framework enshrined by a given paradigm. Hence KP, on its own, does not have the resources to defeat relativism.

It might be thought that such a conception of same- $N K$ relations is incompatible with semantic externalism in general, and so must be incompatible with $\mathrm{KP}$ in particular. For surely the very basis of semantic externalism is the thought that the meaning of a natural kind term is just its referent: a mind-independent object or substance whose existence and nature is independent of our theoretical claims about it. But the existence of such fully mind-independent entities is in no way secured by the casual theory of reference. All that the causal theory of reference requires is that reference is secured via causal interaction rather than by description; and so far as I can tell there is nothing in Kuhnian relativism that is incompatible with that claim. ${ }^{14}$

\footnotetext{
${ }^{14}$ Note in this regard that the Putnam of Reason, Truth and History (1981) abandons metaphysical realism but not the causal theory of reference.
} 
Of course, we might add to KP a healthy dose of scientific realism, and insist that the causal interactions that underpin reference to natural kinds are interactions with fully theory-independent objects and substances. But that would be to make an independent metaphysical assumption that is in no way entailed by KP just by itself.

\section{Nontrivial essentialism revisited}

In $§ 3$ I raised the question: how nontrivial is nontrivial essentialism? My answer was 'not very' - at least by the lights of contemporary metaphysics, where de re modality is virtually de rigueur. I also suggested an analogy with Paul's distinction between 'deep' and 'shallow' essentialism about individuals.

We are now in a position to see that KP is entirely consistent with 'shallow' essentialism - not in the sense that natural kind essences are relative to context, but in the sense that they are relative to the taxonomic hierarchy enshrined within a particular scientific theory. Thus, for example, the question of what birds essentially are - where bird is a natural kind - might depend on which taxonomic structure we presuppose: there may turn out to be no uniquely best or correct taxonomic structure that provides a single, correct answer to that question. Nothing in KP, I have argued, rules this out. Similarly, there may be no unique, theory-independent answer to whether this substance is of the same (natural) chemical kind as that one, since, consistent with KP, what constitutes sameness of chemical kind will, if Kuhnian relativism is true, be relative to the taxonomy of a particular paradigm.

I turn, finally, to Brian Ellis's scientific essentialism. As we saw in §2, Ellis claims that ' $[\mathrm{m}]$ etaphysically necessary propositions ... are true in virtue of the essential natures of things' $(2001,235)$ - and that the mark of metaphysical necessity is that it is not 'grounded in ... descriptive language' (ibid.), so that the necessity of 'water is $\mathrm{H}_{2} \mathrm{O}$ ' 'survives' when we replace 'water' with 'this stuff'. If the argument of this paper is correct, however, Ellis has no grounds for thinking that 'non-descriptive' necessity is the mark of necessity that is grounded in 'the essential natures of things'. Consider again shallow essentialism, as applied to individuals. On that view - or at least on Lewis's version of it - while of course a proposition that expresses the essence of some object (Humphrey, say) will be metaphysically necessary, there is no substantive metaphysical sense in which the necessity is 'grounded in' Humphrey's essential nature. For his essential nature is, in turn, grounded in the obtaining of the appropriate counterpart relation, and this in turn is a context-relative matter. There is 
nothing about Humphrey, considered in himself in isolation from his counterparts, that grounds any metaphysical necessity whatever.

The same point applies to shallow essences of natural kinds - which are, I have argued, entirely compatible with KP. On a shallow conception of natural kind essences, the natural kinds that have those essences are relativised to the taxonomic structures within which the relevant kind terms play a role: there is no theoryindependent same-kind relation, and so there are no theory-independent 'essential natures', that might serve as the grounds for metaphysical necessity. Scientific theories do not, on the shallow conception of kind essences, latch onto fully mindindependent essences any more than do claims about Humphrey's essence on the shallow, Lewisian view. To put the point another way, KP - and the a posteriori necessity that it delivers - does not entail that kind essences are mind- or languageindependent simpliciter, which is the result Ellis needs. It entails only that what is metaphysically necessary and what is epistemically necessary can come apart in the case of natural kinds. But, as Lewis's shallow essentialism so clearly demonstrates, metaphysical necessity may itself fail to be a fully mind- and language-independent matter. Contrary to what Ellis claims, analyticity is not the only way for necessary truths to depend on us: KP does not, just by itself, deliver the mind- and languageindependence of natural kind essences. ${ }^{15}$

This is not, of course, to say that KP demands only a shallow kind of essentialism, for of course KP is also entirely compatible with the deeper kind of essentialism that is often - mistakenly, I have argued - taken to be a consequence of it. My claim is only that deep essentialism about natural kinds is an additional metaphysical assumption. Shallow essentialists do not need to take a stand against KP; they merely need to challenge these additional metaphysical assumptions.

\section{References}

Beebee, H. and Sabbarton-Leary, N. (eds) (2010a) The Semantics and Metaphysics of Natural Kinds. New York: Routledge.

-- (2010b) 'On the abuse of the necessary a posteriori', in Beebee and SabbartonLeary 2010a, 159-78.

\footnotetext{
${ }^{15}$ Nor, according to some authors, is a posteriority required for 'real' necessity, in Ellis's sense that necessity is grounded in essence rather than vice versa; see for example Fine 1994 and Oderberg 2007.
} 
-- (2010c) 'Introduction', in Beebee and Sabbarton-Leary 2010a, 1-24.

Bird, A. (2010) 'Discovering the essences of natural kinds', in Beebee and SabbartonLeary 2010a, 125-36.

-- and Tobin, E. (2010) 'Natural kinds', in E. N. Zalta (ed.), The Stanford Encyclopedia of Philosophy (Summer 2010 Edition), $<$ http://plato.stanford.edu/archives/sum2010/entries/natural-kinds/>.

Devitt, M. and Sterelny, K. (1999) Language and Reality: An Introduction to the Philosophy of Language ( $2^{\text {nd }}$ edn.), Cambridge, MA: MIT Press.

Dupré, J. (1993) The Disorder of Things: Metaphyiscal Foundations of the Disunity of Science. Cambridge, Mass.: Harvard University Press.

-- (2004) 'Review of Natural Kinds and Conceptual Change', Notre Dame Philosophical Reviews. Online. Available HTTP: $<$ http://ndpr.nd.edu/review.cfm?id=1439> (accessed 1 January 2011).

Ellis, B. (2001) Scientific Essentialism. Cambridge: Cambridge University Press.

Fine, K. (1994) 'Essence and modality’, Philosophical Perspectives, 8: 1-16.

Griffiths, P. (1999) 'Squaring the circle: natural kinds with historical essences', in R. Wilson (ed.), Species: New Interdisciplinary Essays, Cambridge, MA: MIT Press, 219-28.

Hacking, I. (2007) 'Natural kinds, rosy dawn, scholastic twilight', Royal Institute of Philosophy Supplement, 82: 203-39.

Hendry, R. F. (2010) 'The elements and conceptual change', in Beebee and Sabbarton-Leary 2010a, 137-58.

Khalidi, M. A. (1998) 'Natural kinds and crosscutting categories', Journal of Philosophy, 95: 33-50.

Kitcher, P. (1984) 'Species', Philosophy of Science, 51: 308-33.

Kripke, S. (1980) Naming and Necessity. Oxford: Basil Blackwell.

Kuhn, T. S. (1970) The Structure of Scientific Revolutions (2 ${ }^{\text {nd }}$ edn.). Chicago: Chicago University Press.

-- (1990) 'The road since Structure', Proceedings of the Biennial Meeting of the Philosophy of Science Association, vol. II: 3-13.

LaPorte, J. (2004) Natural Kinds and Conceptual Change. Cambridge: Cambridge University Press.

-- (2010) 'Theoretical identity statements, their truth, and their discovery', in Beebee and Sabbarton-Leary 2010a, 104-24. 
Lewis, D. K. (1983) 'Postscripts to "Counterpart theory and quantified modal logic", Philosophical Papers, Vol. I. Oxford: Blackwell.

-- (1986) On the Plurality of Worlds. Oxford: Blackwell.

Mumford, S. (2005) 'Kinds, essences, powers', Ratio, 18: 420-36.

Oderberg, D. S. (2006) Real Essentialism. New York: Routledge.

Paul, L. A. (2006) 'In defense of essentialism', Philosophical Perspectives, 20: 33372.

Pauling, L. (1970) General Chemistry: An Introduction to Descriptive Chemistry and Modern Chemical Theory $\left(3^{\text {rd }}\right.$ edn.). San Fransisco: W. H. Freeman.

Putnam, H. (1975) 'The meaning of “meaning”, , in K. Gunderson (ed.), Language, Mind and Knowledge, Minnesota Studies in the Philosophy of Science VII, Minneapolis: Minnesota University Press. Reprinted in Putnam, Mind, Language and Reality: Philosophical Papers, vol. II, Cambridge: Cambridge University Press, 1979, 215-71.

-- (1981) Reason, Truth, and History. Cambridge: Cambridge University Press.

Quine, W. V. (1953) 'Three grades of modal involvement', Proceedings of the $11^{\text {th }}$ International Congress of Philosophy, 14; reprinted in Quine, The Ways of Paradox and Other Essays (revised and enlarged edition), Cambridge, MA: Harvard University Press, 1976, 158-76.

Salmon, N. (2005) Reference and Essence, $2^{\text {nd }}$ edn. Amherst, NY: Prometheus Books. Soames, S. (2007) 'What are natural kinds?', Philosophical Topics, 35, 329-42.

Tobin, E. (2010) 'Crosscutting natural kinds and the hierarchy thesis', in Beebee and Sabbarton-Leary 2010a, 179-91. 